\title{
The Effect of Oxidized Lipids in the Diet on Serum Lipoprotein Peroxides in Control and Diabetic Rats
}

\author{
llona Staprāns, Joseph H. Rapp, Xian-Mang Pan, and Kenneth R. Feingold \\ The Department of Veterans Affairs Medical Center and the Departments of Surgery and Medicine, \\ University of California, San Francisco, California 94121
}

\begin{abstract}
The levels of oxidized serum lipoproteins are increased in humans and animals with diabetes. We have examined the contribution of dietary oxidized lipids on the levels of oxidized lipoproteins. In both control and streptozocin induced diabetic rats, the oxidized lipid content of mesenteric lymph chylomicrons (CM) increased when increasing quantities of oxidized lipids were administered intragastrically. However, at all levels of administered oxidized lipids, the quantity of oxidized lipids in CM was greater in the diabetic animals. These results indicate that oxidized lipids are absorbed and packaged into $\mathrm{CM}$ and suggest that there is increased absorption of oxidized lipids in diabetic animals. In nondiabetic rats fed a fat-free diet, the levels of oxidized lipids in their serum lipoproteins were very low. When oxidized lipids were added to the diet, the quantity of peroxides in serum lipoproteins increased about fivefold. In diabetic animals fed a fat-free diet, there were also very low levels of oxidized lipids in their serum lipoproteins, and there was no difference between control and diabetic rats. However, when diabetic animals were fed a diet containing oxidized lipids, the quantity of oxidized lipids in their serum lipoproteins increased 16-fold and were significantly greater than in controls. Thus, in both control and diabetic rats the quantity of oxidized lipids in the diet largely determines the levels of oxidized lipids in circulating lipoproteins. However, in diabetic animals the effect of diet is more pronounced. Together with the CM studies, these results demonstrate that dietary oxidized lipids make a major contribution to the levels of oxidized lipids in circulating lipoproteins and indicate that increased absorption of oxidized lipids in diabetic animals may play a role in the elevation of oxidized lipoproteins observed in this disorder. ( $J$. Clin. Invest. 1993. 92:638-643.) Key words: lipid peroxides • oxidized dietary fat $\bullet$ serum lipoproteins $\bullet$ chylomicron
\end{abstract}

\section{Introduction}

Atherosclerosis is a major cause of the morbidity and mortality associated with diabetes. The Framingham and other studies have shown that the incidence of cardiovascular disease is significantly increased in diabetes even when adjusted for the other known risk factors for atherosclerosis $(1,2)$. This indicates that diabetic patients have an increased risk of vascular disease that is not simply the result of an increased prevalence of risk factors, but rather that diabetes is an independent risk

Address correspondence to Ilona Staprāns, Ph.D., Lipid Research Laboratory (151L), VA Medical Center, San Francisco, CA 94121.

Received for publication 29 April 1992 and in revised form 2 December 1992.

The Journal of Clinical Investigation, Inc.

Volume 92, August 1993, 638-643 factor for vascular disease. The mechanism by which diabetes increases the risk of atherosclerosis remains speculative despite intensive investigative efforts.

Recent studies have shown that the oxidation of lipoproteins may play a key role in atherogenesis (3-5). Lipid peroxidation converts lipoproteins to a more atherogenic form (3-5). Oxidized LDL and other lipoproteins, including oxidized $\beta$ VLDL (6), are taken up more rapidly by macrophages, leading to foam cell formation. In addition, these oxidized lipoproteins cause increased cytotoxicity to endothelial cells in culture, which could result in endothelial injury (7). Moreover, oxidized LDL has been shown to stimulate the release of chemotactic proteins, cytokines, and growth factors from endothelial and other cells $(3-5,8-10)$, resulting in migration of monocytes, maturation of monocyte/macrophages, foam cell formation, and proliferation of smooth muscle cells.

Several studies have demonstrated that the lipoproteins isolated from both humans $(11,12)$ and experimental animals with diabetes (13-15) are oxidized to a greater extent than lipoproteins from controls. In rats, oxidized lipoproteins were found in VLDL + LDL fraction (15). Thus, diabetes is associated with the increased presence of oxidized serum lipoproteins, and these lipoproteins have the potential for causing tissue damage and lipid accumulation in the arterial wall. The mechanism by which diabetes results in increased levels of lipid peroxides in serum lipoproteins is unknown. Leading hypotheses that could account for the increased oxidation of lipoproteins include $(a)$ diabetes stimulates peroxide-producing systems such as lipoxygenase $(16),(b)$ in diabetes there is a decrease in the antioxidant content of certain tissues, resulting in a decreased protection against oxidation (17-19), (c) secondary to diabetes there is an increase in tissue damage, resulting in increased oxidation $(20,21)$, and $(d)$ in diabetes modification of lipoproteins by glucose enhances the oxidation of lipoproteins (22).

Another possibility is that oxidized lipids in the diet could be a contributing factor to the increase of oxidized lipoproteins found in diabetes. Numerous studies have shown that diabetes alters the structure and function of the small intestine and that these changes result in increased absorption of a variety of substances including lipids (23-25). We have therefore investigated the effect of oxidized dietary lipids on the levels of oxidized lipoproteins in both the lymph and serum of control and diabetic rats.

\section{Methods}

Materials. Streptozocin, 2-thiobarbituric acid, 1,1,3,3-tetramethoxypropane, vitamin $\mathrm{E}$, linoleic acid, and $\mathrm{D}_{2} \mathrm{O}$ were obtained from Sigma Chemical Co., St. Louis, MO. Ketodiastix were obtained from Ames Division, Miles Laboratory, Elkhart, IN. Vitamin E-depleted and natural corn oil were purchased from ICN Pharmaceuticals, Costa Mesa, CA. Lipid peroxide kit (LPO) was obtained from Kamiya Biomedical 
Co., Thousand Oaks, CA. $1-{ }^{14} \mathrm{C}$-linoleic acid and glycerol tri $\left(9-{ }^{3} \mathrm{H}\right)$ oleate were purchased from New England Nuclear, Boston, MA.

Animals. Female Sprague-Dawley rats (180-200 g) were purchased from Bantin and Kingman Inc. (Fremont, CA) and were maintained on reverse 12-h light cycle (0300-1500 dark, 1500-0300 light). Diabetes was induced in rats by injecting, after an overnight fast, $40 \mathrm{mg} / \mathrm{kg}$ streptozocin i.p. in $1 \mathrm{M}$ sodium citrate buffer, $\mathrm{pH}$ 4.5. The urine of these animals was analyzed with Ketodiastix, and animals that did not have at least $1 \%$ glycosuria at all times were eliminated from the study. Control animals were injected with $1 \mathrm{M}$ sodium citrate and were maintained under similar conditions. Animals were studied $14 \mathrm{~d}$ after streptozocin treatment and were fasted for $6 \mathrm{~h}$ before all experiments. All animal studies were performed in accordance with institutional policies, and all procedures were approved by the Subcommittee on Animal Studies.

Diets. Control and diabetic rats were maintained on regular rat chow supplied by Simonsen Laboratories, Gilroy, CA. Alternatively, $10 \mathrm{~d}$ after streptozocin injection, diabetic rats and their controls were fed for 4-5 d either a lipid-free diet consisting of $65 \%$ sucrose, $20 \%$ casein, $4 \%$ salt, $11 \%$ alpha cell mix and vitamins or the same diet to which either natural corn oil (low peroxide; $4.7 \mathrm{nmol}$ peroxide $/ \mathrm{mg}$ oil) or vitamin E-depleted corn oil ( high peroxide; $82.5 \mathrm{nmol}$ peroxide $/ \mathrm{mg}$ oil) was added.

Isolation of serum lipoprotein fractions. Previously it has been shown that in diabetic rat serum, lipid peroxides are in VLDL and LDL, but not in the HDL fractions (15). Since rats contain very low amounts of LDL, all serum lipoprotein oxidation measurements in our studies were done on combined fractions containing VLDL + LDL. For each measurement, lipoproteins were obtained from $9 \mathrm{ml}$ serum (pooled from two rats) after adjusting the density to 1.063 with $\mathrm{KBr}$ and centrifuging at $5 \times 10^{6} \mathrm{~g}$ for $18 \mathrm{~h}$ at $14^{\circ} \mathrm{C}$. The lipid layer was removed, dialyzed against $0.15 \mathrm{M} \mathrm{NaCl}$ containing $0.5 \mathrm{mM}$ EDTA and $0.5 \mu \mathrm{M}$ butylatedhydrohytoluene (BHT), ${ }^{1}$ and analyzed for oxidation immediately. When serum samples were examined for chylomicrons by centrifuging for $20 \mathrm{~min}$ at $5 \times 19^{6} \mathrm{~g}$ min before $\mathrm{KBr}$ addition, no significant amounts of chylomicrons were isolated.

Chylomicron preparation. Chylomicrons were isolated from rat mesenteric lymph using the procedure described previously (26). Rats were intragastrically administered a single bolus of a lipid emulsion consisting of $3 \mathrm{ml}$ of oil and nonlipid milk ( $1: 2, \mathrm{vol} / \mathrm{vol})$ dispersed with a Polytron homogenizer (Brinkmann Instruments, Westbury, NY). The following oils were used for gastric intubation: natural corn oil with low peroxide content ( $4.7 \mathrm{nmol}$ peroxide $/ \mathrm{mg}$ oil); commercially obtained vitamin E-depleted corn oil with medium peroxide content ( $82.5 \mathrm{nmol}$ peroxide/mg oil); and vitamin E-depleted corn oil that had been heated for $1 \mathrm{~h}$ at $100^{\circ} \mathrm{C}$ (high peroxide content, $120.0 \mathrm{nmol}$ peroxide $/ \mathrm{mg}$ oil). The rats were restrained, and chyle was collected on ice for $8 \mathrm{~h}$. During this period rats were allowed to drink water and were periodically injected subcutaneously with $0.15 \mathrm{M}$ saline to maintain hydration. Chylomicrons were isolated from lymph by flotation in an SW-40 rotor (Beckman Instr. Inc., Fullerton, CA) for $5 \times 10^{6} \mathrm{~g}$ for $1 \mathrm{~h}$ at $12^{\circ} \mathrm{C}$. All samples were stored in $1 \mathrm{mM}$ EDTA under nitrogen. In some experiments, $0.1 \mathrm{mCi}$ glycerol tri $\left(9-{ }^{3} \mathrm{H}\right)$ oleate and oxidized or nonoxidized $\left[{ }^{14} \mathrm{C}\right]$ linoleic acid $(0.02 \mathrm{mCi})$ was added to the vitamin E-depleted corn oil. Oxidation of linoleic acid was carried out as described by Boeynaems et al. for preparation of oxidized arachidonic acid $(27) .\left[{ }^{14} \mathrm{C}\right]$ Linoleic acid was oxidized for $2 \mathrm{~h}$ in methanol in the presence of $5 \mu \mathrm{M} \mathrm{Cu}_{2} \mathrm{SO}_{4}$ and 5-10 mg linoleic acid carrier. Measurement by GLC (28) indicated that more than $95 \%$ of the linoleic acid was oxidized. For partial purification, the oxidized linoleic acid was subjected to thin layer chromatography, reisolated, and then used immediately in the intubation mixture (28).

Analytic methods. Triglycerides in chylomicrons and the LDL + VLDL lipoprotein fraction were determined by the method of

1. Abbreviations used in this paper: BHT, butylatedhydrohytoluene; CM, chylomicrons; TBARS, thiobarbituric acid reactive substances.
Fletcher (29). Cholesterol levels were determined using Sigma diagnostic kit (procedure 351). Protein was determined by the method of Lowry et al. (30). Lipid oxidation was estimated by measuring both lipid peroxides and lipid peroxide decomposition products. Lipid peroxides were estimated by a colorimetric method as specified by the manufacturer using a commercially available kit (LPO) from Kamiya Biomedical Co. The method is based on a hemoglobin catalyzed reaction of peroxides with a methylene blue derivative that specifically quantitates lipid peroxides by forming an equal molar concentration of methylene blue (31). Cumene hydroperoxide was used as a standard. Lipid peroxide decomposition products, which consist of a variety of aldehydes, were measured as thiobarbituric acid reactive substances (TBARS) (32).

Student's $t$ test was used to test for the significance between means. Results are reported as means $\pm \mathrm{SE}$.

\section{Results}

Effect of diabetes on oxidized serum lipoproteins. When fed standard rat chow, serum lipoproteins (LDL + VLDL) from diabetic rats had a greater quantity of TBARS than lipoproteins from control rats $(1.04 \pm 0.13 \mathrm{nmol} / \mathrm{mg}$ cholesterol in controls vs. $1.75 \pm 0.31 \mathrm{nmol} / \mathrm{mg}$ cholesterol in diabetic rats; $P$ $<0.05$ ) (Fig. 1 $A$ ). This observation is in agreement with the published results of Morel et al. (15) that demonstrated increased TBARS in rats with streptozocin-induced diabetes. The measurement of TBARS is the most widely used method for estimating lipid oxidation; however, it may not be specific or quantitative since the generated aldehydes may be water soluble and not remain with the lipoproteins during the isolation procedure. To confirm that lipoproteins isolated from diabetic rats are oxidized to a greater extent than those from control rats, we estimated lipoprotein oxidation by directly measuring lipid peroxides in serum lipoproteins using a quantitative and stoichiometric colorimetric method (31). As shown in Fig. $1 B$, with this method the lipoproteins from diabetic rats contained 10 -fold more lipid peroxides than did those from control rats $(1.97 \pm 1.57 \mathrm{nmol} / \mathrm{mg}$ cholesterol in controls vs. $19.62 \pm 6.82 \mathrm{nmol} / \mathrm{mg}$ cholesterol in diabetic rats; $P$

A. TBARS in serum VLDL + LDL

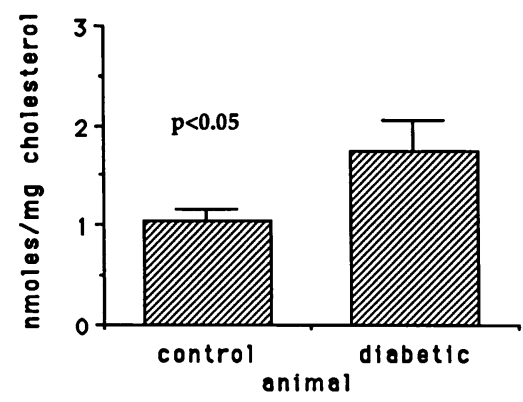

B. Peroxides in serum VLDL + LDL

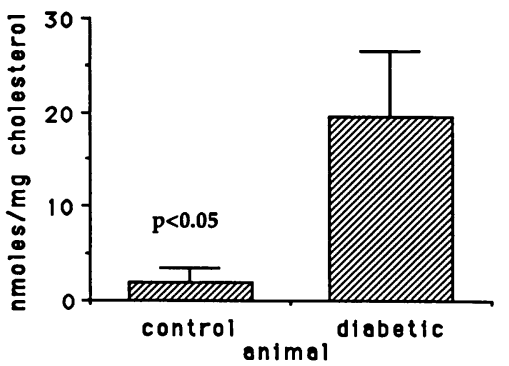

Figure 1. TBARS $(A)$ and lipid peroxide $(B)$ content of VLDL + LDL lipoprotein fraction isolated from the serum of control and diabetic rats fed a regular rat chow diet. All data are represented as means $\pm \mathrm{SE}$ and there were five to six serum samples in each group. Each sample represents serum pooled from two rats. 
$<0.05$ ). Thus, using two different methods for estimating lipoprotein oxidation the lipoproteins isolated from diabetic rats were more oxidized than lipoproteins isolated from control rats.

Effect of dietary oxidized lipids on the peroxide content of serum lipoproteins. To determine the contribution of oxidized lipids in the diet to the content of oxidized lipids in serum lipoproteins, control and diabetic rats were fed diets containing different quantities of oxidized lipid. Since the oxidized lipid content of commercially available standard rat chow is not controlled, we used synthetic diets prepared in our laboratory. Fig. 2 shows serum peroxide concentrations in control rats. When rats were fed a lipid-free diet (sucrose diet), the levels of peroxides in serum lipoproteins were low $(1.00 \pm 0.09 \mathrm{nmol} /$ mg cholesterol). Similarly, when control rats were fed a diet containing 5\% corn oil containing low peroxides $(4.7 \mathrm{nmol}$ peroxide/g oil), the quantity of peroxides in the serum lipoproteins were also low $(0.87 \pm 0.11 \mathrm{nmol} / \mathrm{mg}$ cholesterol $)$. However, when the lipid-containing diet had high quantities of peroxide ( $5 \%$ oil, $82.5 \mathrm{nmol}$ peroxide/g oil), the quantity of peroxides in the lipoproteins increased almost fivefold $(1.00 \pm 0.09 \mathrm{nmol} / \mathrm{mg}$ cholesterol vs. $5.34 \pm 0.50 \mathrm{nmol} / \mathrm{mg}$ cholesterol; $P<0.001)$. Measurements of TBARS confirmed these results. TBARS increased twofold when oxidized lipid-containing diet was fed to the animals instead of a lipid-free sucrose diet. Thus, in control animals the quantity of oxidized lipids in the diet influences the concentration of peroxides in the serum lipoproteins.

In diabetic animals (Fig. 3) fed a lipid-free diet (sucrose diet), which of course contained no oxidized lipid, there were also very low levels of peroxides in the lipoproteins. In fact, the concentration of peroxides in the lipoproteins of diabetic animals fed the lipid-free diet was not different from the serum peroxide concentration observed in controls (Fig. 2). Thus, the increase in the quantity of oxidized lipids in serum lipoproteins of chow-fed diabetic animals (Fig. 1) disappears when animals are fed a diet containing no oxidized lipid.

When diabetic rats were fed a diet containing oxidized lipids, the quantity of peroxides in serum lipoproteins increased approximately 16 -fold $(0.70 \pm 0.10 \mathrm{nmol} / \mathrm{mg}$ cholesterol vs. $11.08 \pm 2.01 \mathrm{nmol} / \mathrm{mg}$ cholesterol; $P<0.005$ ) (Fig. 3). As noted above (Fig. 2), in control animals fed oxidized lipid at the same concentration, the quantity of peroxides in the serum

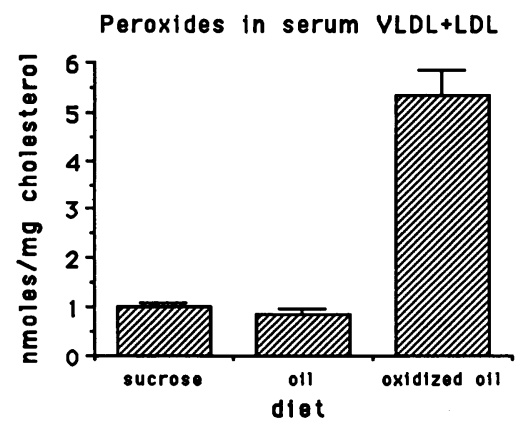

Figure 2. Peroxide content of VLDL + LDL lipoprotein fraction isolated from the serum of control rats fed for 5 $\mathrm{d}$ the following diets:

(a) fat-free sucrose diet, (b) sucrose diet to which $5 \%$ oil containing low lipid peroxides $(4.7$ $\mathrm{nmol} / \mathrm{mg}$ oil) was added, and $(c)$ sucrose diet to which $5 \%$ oil

containing high lipid peroxides $(82.5 \mathrm{nmol} / \mathrm{g}$ oil $)$ was added. All data are represented as means $\pm \mathrm{SE}$, and there were five serum samples in each group. Each sample was derived from serum pooled from two rats. $P<0.001$ when control group fed a fat-free diet was compared with the control group fed oxidized fat diet.

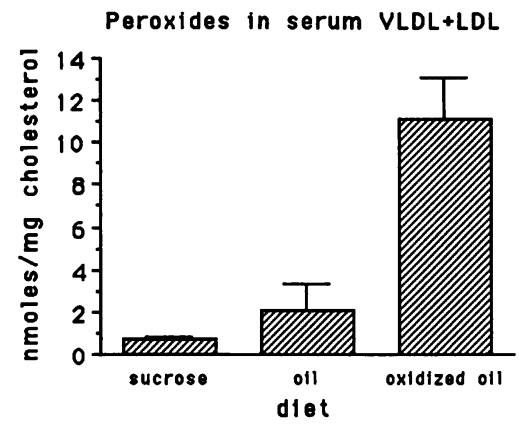

Figure 3. Peroxide content of VLDL + LDL lipoprotein fraction isolated from the serum of diabetic rats fed for 5 $\mathrm{d}$ the following diets:

(a) fat-free sucrose diet, (b) sucrose diet to which $5 \%$ oil containing low lipid peroxides $(4.7$ $\mathrm{nmol} / \mathrm{mg}$ oil) was added, and $(c)$ sucrose diet to which $5 \%$ oil

containing high lipid peroxides $(82.5 \mathrm{nmol} / \mathrm{g}$ oil $)$ was added. All data are represented as means \pm SE, and there were five serum samples in each group. Each sample was derived from serum pooled from two rats. $P<0.005$ when a diabetic group fed a fat-free diet was compared with the diabetic group fed an oxidized fat diet; $P<0.05$ when control group fed an oxidized diet (Fig. 2) was compared with the diabetic group fed the same diet.

lipoproteins increased only by fivefold. Moreover, the quantity of lipid peroxides in the serum of diabetic animals was twofold higher than in controls fed the same diet $(P<0.05)$. Similarly, TBARS increased threefold when rats were fed oxidized-lipidcontaining diet instead of a sucrose diet.

In diabetic rats, the serum peroxide content was low when fed a fat-free sucrose diet and slightly increased when oil containing small amounts of peroxides was added to the sucrose diet (Fig. 3). However, this increase ( $2.1 \pm 0.6 \mathrm{nmol}$ peroxide/ mg cholesterol) did not achieve statistical significance. Additionally, the increase was much less than that observed with a diet containing high quantities of peroxides in the oil $(11.08 \pm 2.01 \mathrm{nmol}$ peroxide $/ \mathrm{mg}$ cholesterol). Since the lipid content in the diet was similar, these results indicate that the increased peroxides in serum lipoproteins of diabetics result from the ingested oxidized lipids and not from the total quantity of lipid in the diet.

Additionally, it can be seen that while both control and diabetic animals demonstrate an increase in the concentration of peroxides in lipoproteins in response to dietary oxidized lipids, the extent of the increase is significantly greater in diabetic animals, suggesting that they are more susceptible to dietary oxidized lipids.

Fig. 4 shows a dose-response curve of the effect of adding increasing quantities of oxidized lipids to the diet on the concentration of peroxides in circulating lipoproteins. There is a

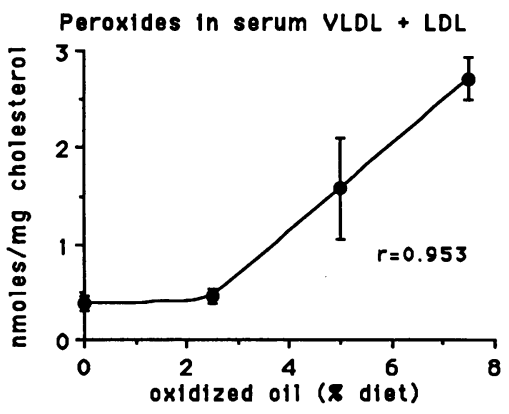

Figure 4. Dose response curve of the effect of increasing amounts of lipid peroxides in the diet on the serum lipid peroxides in VLDL + LDL lipoprotein fraction. Control rats were fed for $5 \mathrm{~d}$ a sucrose diet to which increasing amounts of lipid peroxide containing oil ( 82.5 $\mathrm{nmol} / \mathrm{g}$ oil) were added. All data are represented as means $\pm \mathrm{SE}$, and there were four serum samples in each group. Each sample was serum pooled from two rats. 
strong correlation between the quantity of peroxides in the diet and the concentration of peroxides in the circulating lipoproteins $(r=0.953, P<0.001)$, further suggesting that dietary peroxides are an important source of oxidized lipid in serum lipoproteins. Interestingly, there was no increase in serum lipoprotein peroxides when the oil content in the diet was increased from $0.0 \%$ to $2.5 \%$, raising the possibility that there is a threshold of oxidized lipid intake below which the peroxide content of serum lipoproteins is not altered. However it is also possible that with a more sensitive assay procedure low quantities of dietary oxidized lipid might be shown to affect the quantity of oxidized lipoproteins.

The effect of dietary oxidized lipids on the peroxide content of chylomicrons from continuously collected intestinal lymph. To determine directly whether diabetic rats absorb a greater quantity of oxidized lipid than do the controls, intestinal lymph was continuously collected from control and diabetic rats for $8 \mathrm{~h}$ after the intragastric administration of varying amounts of lipid peroxides. During the 8-h period of collection, the quantity of triglycerides secreted in the lymph of diabetic and control rats was similar $(506 \pm 67 \mathrm{mg}$ in diabetics vs. $456 \pm 26 \mathrm{mg}$ triglyceride in controls). Fig. 5 illustrates that in control rats the quantity of lipid peroxides in chylomicrons isolated from the collected lymph increases with increasing peroxide content of the intragastrically administered oil. When expressed as nmol peroxide/mg triglyceride, the peroxides in lymph chylomicrons was $0.380 \pm 0.06 \mathrm{nmol} / \mathrm{mg}$ triglyceride in the low peroxide group vs. $0.580 \pm 0.01 \mathrm{nmol} / \mathrm{mg}$ triglyceride in the high peroxide group $(P<0.01)$. The results indicate that dietary peroxides are absorbed and packaged into chylomicrons.

In diabetic animals, a similar increase in the quantity of peroxides in chylomicrons in response to increasing amounts of peroxide administration was observed (Fig. 5). When chylomicrons isolated from diabetic animals were compared with chylomicrons from controls, lipid peroxides were significantly increased in the medium and high peroxide groups: $0.640 \pm 0.04$ vs. $0.490 \pm 0.03 \mathrm{nmol}(P<0.005)$ in the medium peroxide group and $0.830 \pm 0.02$ vs. $0.580 \pm 0.01 \mathrm{nmol}(P$

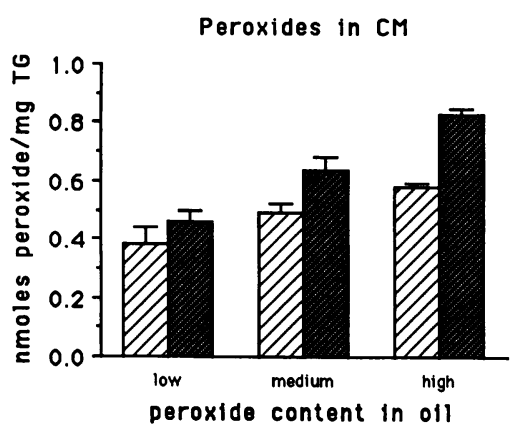

Figure 5. Lipid peroxide content of chylomicrons (CM) from control and diabetic rats. Rats were administered oil containing increasing amounts of lipid peroxides. Low, medium, and high peroxide oil contained 4.7 , 82.5 , and $120.0 \mathrm{nmol}$ peroxide/mg oil, respectively. Lymph was collected for $\mathbf{8 h}$ for chy-

lomicron isolation. All data are expressed as nmol peroxide/mg chylomicron triglyceride and are represented as means \pm SE. There were five rats in each group. $P<0.005$ when control group fed a medium peroxide oil diet was compared with the diabetic group fed the same diet; $P$ $<0.001$ when control group fed a high peroxide diet was compared with the diabetic group fed the same diet; $P<0.01$ when control group fed high peroxide diet was compared with the control group fed low peroxide diet; $P<0.005$ when diabetic group fed a high peroxide diet was compared with the diabetic group fed the low peroxide diet. $\checkmark$ control; $\mathbf{t}$ diabetic.
$<0.001)$ in the high peroxide group. Similar results were obtained when TBARS in chylomicrons were measured: high peroxide controls, $0.59 \pm 0.04 \mathrm{nmol} / \mathrm{mg}$ triglyceride; high peroxide diabetics, $0.81 \pm 0.02 \mathrm{nmol} / \mathrm{mg}$ triglyceride; $P<0.001$. Because the difference between the quantity of oxidized lipid in chylomicrons isolated from control and diabetic rats is greatest when the peroxide content in the oil is the highest, it is likely that the peroxides in lymph chylomicrons are primarily derived from the diet and not from oxidation in the small intestine.

Thus, after the intragastric administration of the same quantity of total lipid peroxides, lymph chylomicrons from diabetic animals contained significantly more lipid peroxides than did chylomicrons from controls.

The effect of ${ }^{14} \mathrm{C}$-labeled dietary oxidized linoleic acid on the ${ }^{14} \mathrm{C}$-labeled linoleic acid content of chylomicrons from continuously collected intestinal lymph. To further demonstrate that diabetic rats absorb greater quantities of oxidized lipid than control rats, intestinal lymph was collected from control and diabetic rats for $8 \mathrm{~h}$ after the intragastric administration of oil containing oxidized $\left[{ }^{14} \mathrm{C}\right]$ linoleic acid. $\left[{ }^{3} \mathrm{H}\right]$ Triolein, which is not easily oxidized, was simultaneously added to the oil to correct for variations in the quantity of lymph collected. When the ratio of oxidized $\left[{ }^{14} \mathrm{C}\right]$ linoleic acid to $\left[{ }^{3} \mathrm{H}\right]$ triolein $\left({ }^{14} \mathrm{C} /{ }^{3} \mathrm{H}\right)$ recovered in chylomicrons was examined in control and diabetic rats, we found that the ratio was increased $(2.67 \pm 0.37)$ in diabetic rats when compared with controls $(1.34 \pm 0.06), P<0.01$ ( Table I). In contrast, the ratio was the same in control ( $1.55 \pm 0.21)$ and diabetic animals $(1.50 \pm 0.12)$ when nonoxidized $\left[{ }^{14} \mathrm{C}\right]$ linoleic acid was administered. These data further demonstrate that diabetic animals have an increased absorption of oxidized dietary lipids with more oxidized lipids recovered in the lymph chylomicrons of diabetic animals.

\section{Discussion}

Several studies have shown that the quantity of oxidized lipids in serum lipoproteins is increased in diabetic patients $(11,12)$ and in animals with experimentally induced diabetes (13-15). Numerous in vitro and in vivo studies suggest that oxidized lipoproteins play an important role in atherogenesis (3-5). Oxidized lipoproteins lead to an increase in lipid uptake and deposition in macrophages, resulting in foam cell formation (3-5). Additionally, oxidized lipoproteins are cytotoxic to endothelial cells in culture (7). Furthermore, oxidized lipoproteins stimulate the release of cytokines and growth factors that could potentiate the atherogenic process $(3-5,8-10)$. An increase in oxidized lipoproteins could therefore contribute through sev-

Table I. Ratio of $\left[{ }^{14} \mathrm{C}\right.$ Linoleic Acid $\left.{ }^{3} \mathrm{H}\right]$ Oleic Acid Label Recovered in Chylomicrons

\begin{tabular}{llll}
\hline \multicolumn{2}{c}{ Nonoxidized linoleic acid } & \multicolumn{2}{c}{ Oxidized linoleic acid } \\
\hline Control rat* & $1.55 \pm 0.21$ & Control rat $^{\ddagger}$ & $1.34 \pm 0.06$ \\
Diabetic rat* $^{*}$ & $1.50 \pm 0.12$ (NS) & Diabetic rat $^{\ddagger}$ & $2.67 \pm 0.33^{\S}$
\end{tabular}

Control and diabetic rats were administered nonoxidized $\left[{ }^{3} \mathrm{H}\right]$ oleic acid simultaneously with either oxidized or nonoxidized $\left[{ }^{14} \mathrm{C}\right]$ linoleic acid. Lymph was collected for $8 \mathrm{~h}$ and the ${ }^{14} \mathrm{C} /{ }^{3} \mathrm{H}$ in the lymph was determined. ${ }^{*}$ Values represent an average from four preparations. ${ }^{\ddagger}$ Values represent an average from five preparations. ${ }^{\S} P<0.01$. 
eral mechanisms to the increased risk of atherosclerosis that is associated with diabetes.

The origin of the increase in oxidized lipoproteins in diabetes is unknown. In the present study we have examined the effect of oxidized lipids in the diet on the levels of serum oxidized lipoproteins and the possibility that an increased absorption of lipid peroxides in the diabetic is responsible for the elevated levels of lipid peroxides in the serum of diabetics.

In control animals, the quantity of oxidized lipid in the diet directly correlated with the concentration of oxidized lipid in the serum lipoproteins $(r=0.953, P<0.001)$. Animals that were fed a diet containing no oxidized lipid had very little oxidized lipid in serum lipoproteins, while animals fed a diet containing increasing quantities of oxidized lipid had increasing concentrations of oxidized lipid in their serum lipoproteins. These results indicate that dietary oxidized lipids play an important role in determining the concentration of oxidized lipid in serum lipoproteins. Moreover, the quantity of oxidized lipid in chylomicrons isolated from the mesenteric lymph drainage of the small intestine also closely correlated with the amount of oxidized lipid administered to the animals $(r=0.989, P$ $<0.01)$. These results indicate that oxidized lipids in the diet are absorbed by the small intestine and are transported in chylomicrons to the circulation, where they contribute to the total body pool of oxidized lipids. Given that our studies demonstrate that oxidized lipids in the diet affect not only the concentration of oxidized lipid in chylomicrons but also the serum VLDL + LDL lipoprotein fraction, one can speculate that the oxidized lipid in chylomicrons is either delivered to the liver. where it is repackaged and secreted in endogenous lipoproteins or transferred in the circulation to other lipoprotein particles.

The presence of oxidized lipid in rat lymph has been investigated previously with contradictory results. Several investigators have not found any oxidized lipids in the lymph and have concluded that deperoxidation takes place in the intestinal mucosa (33-35). Recently, however, Aw et al. (36), by measuring TBARS, have demonstrated lipid peroxidation in the rat lymph. The degree of lipid peroxidation correlated with the GSH content of the intestinal mucosa cells. Decreasing intestinal GSH levels by feeding inhibitors of GSH transferase resulted in an increase in absorption and transport into the lymph of oxidized lipids. These results indicate that the absorption and transport of oxidized lipids by the small intestine can vary depending upon GSH levels in the small intestine, and such differences might account for the conflicting observations regarding the presence of oxidized lipids in the lymph. Recently we have demonstrated that dietary lipid peroxides are incorporated into rat lymph chylomicrons and these lipid peroxides have a significant influence on the metabolism of plasma chylomicrons in rats (37).

As reported previously by Morel et al. (15), we also have observed that the concentration of oxidized lipid in the serum lipoprotein fraction $(d<1.063)$ from diabetic rats fed a standard chow was increased in comparison with controls. A main conclusion of the present study is that an increased absorption of dietary oxidized lipids is primarily responsible for the elevated lipid peroxides in the serum of streptozocin-induced diabetic rats. This conclusion is supported by three separate findings. First, in the absence of lipid peroxides in the diet no increase in serum lipid peroxides occurs in the diabetic animals compared with controls. Second, the level of lipid peroxides in the serum of control and diabetic rats closely correlates with the level of lipid peroxides in the diet. However, in the diabetic rat there is a greater elevation of lipid peroxides in the serum than in the control rat when fed a diet containing lipid peroxides. Third, the increased absorption of oxidized lipids by the diabetic rat is directly demonstrated by experiments showing that, following gastric administration of lipid peroxides, diabetic rats absorbed an increased amount of oxidized lipid into their intestinal lymph compared with nondiabetic rats. Taken together, these results indicate that the increased absorption of lipid peroxides contributes to the elevated levels of serum lipid peroxides that characterize the diabetic state. Additionally, diabetic animals are hyperphagic $(23,38)$ and therefore will consume increased quantities of dietary oxidized lipids, which could also contribute to the elevated quantities of lipid peroxides in serum lipoproteins.

The increase in absorption of oxidized lipids by the small intestine in diabetic rats could be due to a number of factors. As discussed above, Aw et al. (36) have shown that decreased GSH levels in the intestinal mucosa lead to an increase in absorption of oxidized lipids by the small intestine. Studies in diabetic rats have shown that there is a decrease in GSH transferase in the small intestine (14) that could lead to decreased GSH levels and thereby increase oxidized lipid absorption. Furthermore, Loven et al. (18) have shown that the activity of the superoxide dismutase, the primary enzyme in reducing hydroperoxide, is decreased in the small intestine of diabetic rats. It is possible that this decrease could also contribute to the increased absorption of oxidized lipids in diabetic rats.

In addition to alterations in the GSH system and oxidative state of the small intestine in diabetic rats, other factors could also contribute to the increased oxidized lipid absorption. Diabetes results in a variety of changes in intestinal lipid metabolism. Both cholesterol and fatty acid synthesis are increased approximately twofold in the small intestine of diabetic animals $(38,39)$. Moreover, the transport of newly synthesized cholesterol from the small intestine to the circulation is increased fourfold in diabetic animals (40). Furthermore, several investigators have shown that the transport of triglyceride from the small intestine to the circulation in the postabsorptive state is also increased by diabetes $(41-43)$. These studies indicate that the flux of lipid from the small intestine to the circulation is enhanced by diabetes, and it is possible that the increase in oxidized lipid transport is related to these alterations in the lipid flux.

Last, diabetes has been shown to affect the absorption of a variety of nutrients. The increased absorption of amino acids, glucose, bile acids, phosphate and fatty alcohols have been demonstrated in diabetic animals $(24,25)$. Of greater relevance is the finding that the absorption of cholesterol is increased in diabetes $(25,44,45)$. A single study also indicates an increase in fatty acid absorption (46). These increases in intestinal absorption have been attributed to increased maximal transport capacity, increased passive permeability, alterations in the intestinal water layer, and increased mucosal mass. Regardless of the exact etiology, it is possible that such changes in the small intestine of diabetic animals also lead to the increased absorption of oxidized lipids.

In summary, the present study demonstrates that the quantity of oxidized lipid in the diet affects the concentration of oxidized lipid in circulating lipoproteins in both control and diabetic rats. In diabetic animals, both food intake and the absorption of dietary oxidized lipids are increased, which could 
account for the increase in the concentration of oxidized lipids in serum lipoproteins. Given the widespread use of fried foods in both commercial and domestic settings, the American diet is rich in thermally oxidized lipid, which could lead to an increased quantity of oxidized lipid in serum lipoproteins, especially in diabetics, and thereby contribute to atherosclerosis both in nondiabetic and diabetic individuals.

\section{Acknowledgments}

The excellent technical assistance of Ms. Kelly Kim and Mr. Arthur Moser is appreciated. Drs. Marvin D. Siperstein and Carl Grunfeld are gratefully acknowledged for the helpful discussions.

This work was supported by the Medical Research Service, Veterans Affairs, National Institutes of Health HL-41470 and Pacific Vascular Research Foundation.

\section{References}

1. Kannel, W. B., and D. L. McGee. 1979. Diabetes and glucose tolerance as risk factors for cardiovascular disease: the Framingham study. Diabetes Care. $2: 120-126$.

2. Feingold, K. R., and M. D. Siperstein. 1986. Diabetic vascular disease. $A d v$. Int. Med. 31:309-340.

3. Steinberg, D., S. Parthasarathy, T. Carew, J. C. Khoo, and J. L. Witztum. 1989. Beyond cholesterol. Modification of low density lipoprotein that increases its atherogenicity. $N$. Engl. J. Med. 320:915-924.

4. Steinberg, D., and J. L. Witztum. 1990. Lipoproteins and atherogenesis. Current concepts. JAMA (J. Am. Med. Assoc.). 246:3047-3052.

5. Witztum, J. L., and D. Steinberg. 1991. Role of oxidized low density lipoprotein in atherogenesis. J. Clin. Invest. 88:1785-1792.

6. Parthasarathy, S., M. T. Quinn, D. C. Schwenke, T. E. Carew, and D. Steinberg. 1989. Oxidative modification of beta-very low density lipoprotein. Arteriosclerosis. 9:398-404

7. Morel, D. W., P. E. DiCorleto, and G. M. Chisolm. 1984. Endothelial and smooth muscle cells alter low density lipoprotein in vitro by free radical oxidation. Arteriosclerosis. 4:357-364.

8. Cushing, S. D., J. A. Berliner, A. J. Valente, M. C. Territo, M. Navab, F. Parhami, R. Gerrity, C. J. Schwartz, and A. M. Fogelman. 1990. Minimally modified low density lipoprotein induces monocyte chemotactic protein 1 in human endothelial cells and smooth muscle cells. Proc. Natl. Acad. Sci. USA. 87:5134-5138.

9. Liao, F., J. A. Berliner, M. Mehrabian, M. Navab, L. L. Demer, A. J. Lusis, and A. M. Fogelman. 1991. Minimally modified low density lipoprotein is biologically active in vivo. J. Clin. Invest. 87:2253-2257.

10. Fox, P. L., G. M. Chisolm, and P. E. DiCorleto. 1987. Lipoprotein-mediated inhibition of endothelial cell production of platelet-derived growth factorlike protein depends on free radical lipid peroxidation. J. Biol. Chem. 262:60466054.

11. Nishigaki, I., M. Hagihara, H. T. Tsunekawa, M. Maseki, and K. Yagi. 1981. Lipid peroxide levels of serum lipoprotein fractions of diabetic patients. Biochem. Med. 25:373-378.

12. Sato, Y., N. Hotta, N. Sakamoto, S. Matsuoka, N. Ohishi, and K. Yagi. 1979. Lipid peroxide level in plasma of diabetic patients. Biochem. Med. 21:104 107.

13. Higuchi, Y. 1982. Lipid peroxides and alpha-tocopherol in rat streptozotocin-induced diabetes mellitus. Acta Med. Okayama. 3:165-175.

14. Pisanti, F. A., Frascatore, S., and G. Papaccio. 1983. Superoxide dismutase activity in the BB rat: a dynamic time course study. Life Sci. 43:1624-1632.

15. Morel, D. W., and G. M. Chisolm. 1989. Antioxidant treatment of diabetic rats inhibits lipoprotein oxidation and cytotoxicity. J. Lipid Res. 30:18271834.

16. McNally, A. K., G. M. Chisolm, D. W. Morel, and M. K. Cathcart. 1990 Activated human monocytes oxidize low-density lipoprotein by a lipoxygenasedependent pathway. J. Immunol. 145:254-259.

17. Matkovics, B., I. Varga, I. Szabo, and H. Witas. 1982. The effect of diabetes on the activities of the peroxide metabolism enzymes. Horm. Metab. Res. 14:77-79.

18. Loven, D. P., H. P. Schedl, L. W. Oberley, H. D. Wilson, L. Brunch, and C. N. Niehaus. 1982. Superoxide dismutase activity in the intestinal mucosa of streptozotocin-diabetic rat. Endocrinology. 111:737-742.
19. Carnovale, C. E., J. A. Monti, V. A. Catania, and M. C. Carrillo. 1990. Possible role of blood insulin levels on glutathione S-transferase activities from different tissues of male rats. Can. J. Physiol. Pharmacol. 68:170-173.

20. Harman, D. 1969. Prolongation of life: role of free radical reactions in aging. J. Am. Geriatr. Soc. 17:721-735.

21. Halliwell, B., and J. M. C. Gutteridge. 1986. Oxygen free radicals and iron in relation to biology and medicine: some problems and concepts. Arch. Biochem. Biophys. 246:510-514.

22. Hunt, J. V., C. C. T. Smith, and S. P. Wolff. 1990. Autoxidative glycosylation and possible involvement of peroxides and free radicals in LDL modification by glucose. Diabetes. 39:1420-1424.

23. Feingold, R. K. 1989. Importance of small intestine in diabetic hypercholesterolemia. Diabetes. 38:141-145.

24. Olsen, W. A., and I. H. Rosenberg. 1970. Intestinal transport of sugars and amino acids in the diabetic rats. J. Clin. Invest. 49:96-105.

25. Thomson, A. B. R., and R. Rajotte. 1983. Effect of dietary modification on the uptake of glucose, fatty acids and alcohols in diabetic rats. Am. J. Clin. Nutr. 38:394-403.

26. Staprans, I., and J. M. Felts. 1989. A possible mechanism for accelerated atherogenesis in male versus female rats. Arteriosclerosis. 9:224-229.

27. Boeynaems, J. M., A. R. Brash, J. A. Oates, and W. C. Hubbard. 1979. Preparation and assay of monohydroxy-eicosatetranoic acids. Anal. Biochem. 104:259-267.

28. Wisneski, J. A., E. W. Gertz, R. A. Neese, and M. Mayr. 1987. Myocardial metabolism of free fatty acids. Studies with ${ }^{14} \mathrm{C}$ labeled substrates in humans. $J$. Clin. Invest. 79:359-366.

29. Fletcher, M. J. 1968. A colorimetric method for estimating serum triglycerides. Clin. Chim. Acta. 22:393-397.

30. Lowry, O. H., N. J. Rosebrough, A. L. Farr, and R. J. Randall. 1951. Protein measurement with the Folin phenol reagent. J. Biol. Chem. 193:265275.

31. Ohishi, N., H. Ohkawa, A. Miike, T. Tatano, and K. Yagi. 1985. A new assay method for lipid peroxides using a methylene blue derivative. Biochem. Int 10:205-211.

32. Morel, D. W., J. R. Hessler, and G. M. Chisolm. 1983. Low density lipoprotein cytotoxicity induced by free radical peroxidation of lipid. J. Lipid Res. 24:1070-1076.

33. Andrews, J. S., W. H. Griffith, J. F. Mead, and R. A. Stein. 1960. Toxicity of air-oxidized soybean oil. J. Nutr. 70:199-210.

34. Bergan, F. G., and H. H. Draper. 1970. Absorption and metabolism of 1- ${ }^{14} \mathrm{C}$-methyl linoleate hydroperoxide. Lipids. 5:976-982.

35. Glavind, J. 1970. Intestinal absorption and lymphatic transport of methyl linoleate hydroperoxide and hydroxyoctadecadinoeate in the rat. Acta DermatoVenereol. 24:3723-3728.

36. Aw, T. Y., M. W. Williams, and L. Gray. 1992. Absorption and lymphatic transport of peroxidized lipids by rat small intestine in vivo: role of mucosal GSH. Am. J. Physiol. 262:G99-G106.

37. Staprans, I., X. M. Pan, M. Miller, and J. H. Rapp. 1993. The effect of oxidation on the chylomicron metabolism in rats. Am. J. Physiol. 264:G561G568.

38. Feingold, K. R., M. H. Wiley, G. MacRae, G. A. Kaysen, P. Y. Schoenfeld, and M. D. Siperstein. 1982. The effect of diabetes mellitus on sterol synthesis in the diabetic rat. Diabetes. 31:388-395.

39. Feingold, R. K., A. Moser, S. Adi, M. Soued, and C. Grunfeld. 1990 Small intestine fatty acid synthesis is increased in diabetic rats. Endocrinology. 127:2247-2252.

40. Feingold, R. K., G. Zsigmond, M. Hughes-Fullford, S. R. Lear, and A. H. Moser. 1985. The effect of diabetes mellitus on the lymphatic transport of intestinal sterols. Metab. Clin. Exp. 34:1105-1109.

41. Steiner, G. S., M. Poapst, and J. K. Davidson. 1975. Production of chylomicron-like lipoproteins from endogenous lipid by the intestine and liver of diabetic dogs. Diabetes. 24:263-271.

42. Risser, T. R., G. M. Reaven, and E. P. Reaven. 1978. Intestinal very low density lipoprotein secretion in insulin-deficient rats. Diabetes. 27:902-908

43. Popper, D. A., Y. Shiau, and M. Reed. 1985. Role of small intestine in pathogenesis of hyperlipidemia in diabetic rats. Am. J. Physiol. 249:G161-G167.

44. Nervi, F. O., A. Gonzalez, and V. D. Valdivieso. 1974. Studies on cholesterol metabolism in the diabetic rat. Metab. Clin. Exp. 23:495-503.

45. Thomson, A. B. R., and R. Rajotte. 1983. Effect of dietary modification on the enhanced uptake of cholesterol in diabetic rats. Am. J. Clin. Nutr. 37:244252.

46. Young, N. L., D. R. Lopez, D. J. McNamara, and G. Benavides. 1985. Evaluation of the contribution of dietary cholesterol to hypercholesterolemia in diabetic rats and of sitosterol as a recovery standard for cholesterol absorption. $J$. Lipid Res. 26:62-69. 